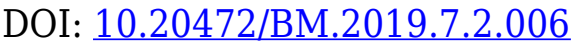

\title{
ENERGY CONSUMPTION AND TOXIC GASES EMISSIONS: WHAT EFFECTS ON ECONOMIC GROWTH IN THE MENA COUNTRIES?
}

\section{BECHIR FRIDHI}

\begin{abstract}
:
The purpose of this paper is to test the Kuznets Environmental Curve (KEC) hypothesis for 10 MENA (Middle East and North Africa) countries during the period 1987-2017. To do this, the translogical functional form has been adopted to estimate the relationship between Toxic Gases (TG) emissions, energy consumption and GDP per capita. The results confirm the presence of KEC, GDP per capita and energy consumption have a positive influence on TG emissions, and the presence of a feedback relationship between GDP per capita and energy consumption. As a result, the environmental framework of the selected countries improves as their level of growth has become more advanced. In addition, to reduce TG emissions, MENA countries are expected to significantly increase the use of renewable energy and a more efficient energy policy.
\end{abstract}

\section{Keywords:}

Economic growth, Energy Consumption, KEC, MENA countries, TG emissions.

JEL Classification: $A 12, A 11, A 12$

\section{Authors:}

BECHIR FRIDHI, Fseg Nabeul, Tunisia, Email: bechir.fridhi2013@gmail.com

\section{Citation:}

BECHIR FRIDHI (2019). Energy Consumption and Toxic Gases Emissions: What Effects on Economic Growth in the MENA Countries?. International Journal of Business and Management, Vol. VII(2), pp. 80-93., 10.20472/BM.2019.7.2.006 


\section{Introduction}

Since the beginning of the 1990s, the environmental dimension has become an increasingly important part of development policies both nationally and internationally. According to the Brundtland Report (1987), sustainable development is one that meets the needs of the present without compromising the ability of future generations to meet their own needs. This cannot take place without the consideration of three dimensions; the economic dimension, the social dimension and the environmental dimension. Indeed, an economic policy aimed at boosting the growth rate will certainly have negative effects on the environment, because such a policy requires in particular a strong use of natural resources. Panayotou (1993) is the first author to have developed the idea that the relationship between TG emissions and economic growth takes the form of an inverted "U" curve, called the KEC. Indeed, environmental degradation will be less important as long as the level of economic growth is higher.

Otherwise, economic literature refers economic growth to the accumulation of factors of production, such as physical capital, labor, human capital, and technical progress. However, many economists, specialists in energy saving, support the idea that these factors of production can only be productive in the presence of energy, then energy is considered as the engine of economic growth. In fact, the causes of environmental degradation are not reduced to just one factor, namely economic growth, but other factors also play a role, such as energy consumption. Indeed, the most used energy sources in the countries of the MENA region are fossil fuels. The latter are the most polluting because the use of gas or oil in economic activity, for example the production of electricity, emits TG into the air and contributes to the greenhouse effect. It is this air pollution that is causing climate change. According to a World Bank report released in 2011, countries in the region will be hard hit by climate change. Because the average rate of warming will be higher than the world average, plus the phenomenon of drought and water stress.

It should be noted that statistics from the World Bank (WDI, 2017) show that TG emissions in MENA countries were 3.6 metric tons per capita in 1990 and 6.2 metric tons per capita in 2017 , an increase of $172 \%$ over two decades. While global average emissions for the same periods (1987 and 2017) are only 4.2 metric tons per capita and 5 metric tons per capita. The upward trend in emissions will be a real problem that countries in the MENA region will have to face, as their international commitments on climate change (2016 Paris Agreement) will force them to work to reduce greenhouse gas emissions. This requires, of course, a 
reduction in the consumption of fossil fuels, knowing that clean energies, known as renewable energies, are not sufficiently developed to succeed in the energy transition, which risks jeopardizing the economic development of the countries in question.

Therefore, promoting sustainable development in MENA countries requires careful analysis of the sources of environmental degradation. Therefore, the purpose of this study is to provide both theoretical and empirical insights into the nature of the relationships that can exist between economic growth, fossil fuel consumption and TG emissions. This leads us to verify the hypothesis of the Kuznets Environmental Curve (KEC) for the selected countries. The reason that motivated us to tackle such a problem is the lack of consensus between the results of the work in this area, as some works have confirmed the hypothesis of the KEC, while others deny it. As such, this contribution is based on a new and appropriate methodology. This is an empirical panel data analysis of 10 MENA countries during the period from 1980 to 2017. In addition, the Translog functional form (Transcendental-Logarithmic) will be used to estimate the relationship between dependent variable (TG emissions) and explanatory variables (GDP per capita, energy consumption). The use of the econometric specifications of the Translog function in panel data is justified for various reasons. This function is flexible; it captures at the same time not only the effect of each explanatory variable on the endogenous variable, but also the nature of the relation between the explanatory variables, as well as the estimation and their quadratic effects. Therefore, the sign of the quadratic term of GDP per capita will be of paramount importance to invalidate or confirm the hypothesis of the KEC.

The article is structured in five sections. A first section, which sets out the problematic and the object of the study. The second section is devoted to a literature review that summarizes the main work on the issue of the relationship between economic growth and the environment. The third section presents the methodology used to treat our problem. The descriptive analysis of data and the presentation and discussion of the results obtained will be the subject of the fourth and fifth sections. Finally, the main conclusions will be summarized in section 6 .

\section{Literature Review}

Since the Panayotou (1993) study, empirical work on the issue of the relationship between economic growth and the environment has continued to flourish. Indeed, Panayotou (1993) attempted, through both theoretical and empirical analysis, to test the hypothesis of the KEC. This hypothesis assumes that the economic-environmental growth relationship takes the form of an inverted "U". Indeed, the empirical study was to highlight the relationship between 
economic development effects on deforestation and air pollution for a sample of developed and developing countries. The results obtained confirm the KEC hypothesis. According to the author, the confirmation of the KEC involves important political consequences. Because, during the development period, the degradation of the environment is inevitable. However, when the economy reaches an advanced level of growth, the environmental framework begins to improve significantly.

In addition, Panayotou (1993) broadened the debate by pushing those interested in the issue of the relationship between economic growth and the environment to deepen their research to better identify the nature of this relationship. As a result, much subsequent work has addressed the same issue by adopting different methodologies than Panayotou (1993), or by introducing other factors considered important for analyzing the sources of environmental degradation. These studies tested the KEC hypothesis using different environmental degradation variables. However, the variable that is often used is carbon dioxide emissions. In terms of economic variables, GDP per capita, energy use is often used, but some studies introduce other additional variables, such as trade openness, population, urbanization, and FDI. Lastly, we note that the results of this empirical work are far from reaching consensus, since some confirm the hypothesis of the KEC when others do not. For example, Du et al. (2012) tested the CEK for the case of the Chinese provinces during the period 1990 to 2007. Using fixed-effect panel data modeling and the general method of moments (GMM), Du et al. (2012) succeeded in rejecting the hypothesis of the KEC. This result is shared by other authors, such as the study by Chandran and Tang (2013), Saboori and Sulaiman (2013), and that of Babu and Datta (2013).

In addition, the Ozcan (2013) study aims to test the KEC hypothesis for a panel of 12 MENA countries during the period 1990-2008. The methodology used is based on advanced methods. Panel data econometrics (Pedroni cointegration, FMOLS, VECM and Granger causality), and the variables studied are TG emissions, energy consumption, GDP and GDP squared. The results obtained are mixed. KEC has been identified only in 3 countries, while in 5 countries the relationship between TG emissions and GDP takes a "U" shape, and in the other 4 countries, the results show that there is no causal link between GDP and TG emissions. On the other hand, much empirical work supports the hypothesis that the relationship between environmental degradation and economic development is in the form of an inverted " $U$ ". Indeed, the methodology adopted by Shahbaz et al. (2014) is the ARDL model for testing a possible cointegration relationship between TG emissions and GDP, GDP squared, energy 
consumption and trade openness. These variables were studied over the period from 1971 to 2010 and in the case of Tunisia.

The results confirm the presence of a wedge between the studied variables and the CEK hypothesis was confirmed. This finding is corroborated by other studies. In addition, Osabuohien et al. (2014) used a different methodology to test the KEC hypothesis using advanced panel data techniques (Pedroni-cointegration, and dynamic OLS, DOLS). The variables selected are TG emissions, GDP, GDP squared, the rule of law, the quality of regulation, government efficiency and economic openness. This study resulted in the confirmation of the KEC hypothesis. In the wake of previous analyzes, this study aims to test the KEC hypothesis for 10 MENA countries during the period 1987-2017, using a new methodology. The latter consists of assuming a functional form of the translog type of the economic-environmental growth relationship.

\section{Methodology}

In order to identify the nature of the relationship between TG emissions, energy consumption and economic growth, we will assume a functional form of Translog type in panel data. Such a function is obtained via the local approximation by a limited development of Taylor of order 2, relating an endogenous variable, the TG emissions, with two exogenous variables which are the energy consumption and the economic growth and this for the case of 10 MENA countries during the period 1987-2017. The use of the Translog functional form makes it possible not only to identify the nature of the relationship between the endogenous variable and the explanatory variables, but also to identify conclusions on cross-effects and quadratic effects, including the one on GDP growth. With regard to the coefficient that captures the cross-effect between GDP and energy use, a positive sign means the existence of a complementarity relationship and a negative sign informs about a substitution relationship. A negative sign of the coefficient associated with the quadratic term of GDP per capita then tells us about the presence of a turning point between TG emissions and the level of economic development. This allows us to test the hypothesis of the KEC hypothesis. It should also be noted that the elasticities associated with the explanatory variables of a Translog function are variable and dependent on the time and the countries in the sample. Indeed, the functional form in panel data of a second order Translog function, as it was developed by Christensen et al. (1973), is defined as follows:

$$
\operatorname{Ln}\left(\mathrm{TG}_{\mathrm{it}}\right)=\mathrm{A}_{\mathrm{it}}+\alpha_{1} \operatorname{Ln}\left(\mathrm{E}_{\mathrm{it}}\right)+\alpha_{2} \operatorname{Ln}\left(\mathrm{GDP}_{\mathrm{it}}\right)+\alpha_{12}\left[\operatorname{Ln}\left(\mathrm{E}_{\mathrm{it}}\right)\right] *\left[\operatorname{Ln}\left(\mathrm{GDP}_{\mathrm{it}}\right)\right]+
$$


$+\frac{1}{2} *\left[\alpha_{22} \operatorname{Ln}\left(\mathrm{GDP}_{\mathrm{it}}^{2}\right)\right]+\frac{1}{2} *\left[\alpha_{11} \operatorname{Ln}\left(\mathrm{E}_{\mathrm{it}}^{2}\right)\right]+\epsilon_{\mathrm{it}}$

Where $\operatorname{Ln}(T G)$ is the natural logarithm of TG emissions (metric tons per capita). The term $A$ is a constant that refers to the temporal and individual effect of each country $\operatorname{Ln}(E)$ is the natural logarithm of energy use (in $\mathrm{Kg}$ of oil equivalent per capita), $\operatorname{Ln}(G D P$ ) is the natural logarithm of the gross domestic product per capita at constant dollar. The indices $i$ and $t$ refer respectively to the individual and temporal dimensioni $\in\{1,2,3 \ldots \ldots 10\}$, and $t \in$ $\{1987,1988,1989 \ldots \ldots 2017\}$. However, $\alpha_{1}, \alpha_{2}, \alpha_{12}, \alpha_{11}, \alpha_{22}$, are parameters to be estimated and in fact refer to the elasticities associated with the different terms of equation (1).

In addition, in order to eliminate the size effect of the sample, output and inputs per worker will be transformed into a difference from the sample mean. The italic letters will be used to design such a difference, so equation (1) will be rewritten as follows:

$$
\begin{gathered}
\operatorname{Ln}\left(T G_{i t}\right)=A_{i t}+\alpha_{1} \operatorname{Ln}\left(E_{i t}\right)+\alpha_{2} \operatorname{Ln}\left(G D P_{i t}\right)+\alpha_{12}\left[\operatorname{Ln}\left(E_{i t}\right)\right] *\left[\operatorname{Ln}\left(G D P_{i t}\right)\right]+ \\
+\frac{1}{2} *\left[\alpha_{22} \operatorname{Ln}\left(G D P_{i t}^{2}\right)\right]+\frac{1}{2} *\left[\alpha_{11} \operatorname{Ln}\left(E_{i t}^{2}\right)\right]+\epsilon_{i t}
\end{gathered}
$$

The parameters of equation (2) will be estimated using panel data econometric techniques using the STATA software. Indeed, two types of models will be estimated, namely the fixedeffect model and the random-effect model. The Hausman test (1978) was used to identify which of these two models was the most appropriate. In addition, the chosen model will be subject to different validity tests. This involves testing for the presence or absence of autocorrelation of errors, heteroscedasticity and multi-collinearity in the panel data. Indeed, if such problems occur, the Feasible Generalized Least Squares (FGLS) method will be used to eliminate them.

\section{Descriptive analysis of the data used}

This study aims to estimate the relationship between TG emissions, energy consumption and economic growth during the period from 1987 to 2017, in the case of a panel of countries in the MENA region. The selected sample comprises 10 countries, namely: Algeria, Bahrain, Egypt, Iraq, Iran, Jordan, Morocco, Saudi Arabia, Tunisia and Turkey. All database World Development Indicators (WDI, 2017) of the World Bank. The variable to be explained is TG emissions, expressed in tones per capita. In the case of the countries studied, Table 1 and Table 2 show that while the average annual TG emissions per capita are 6.2 tones, the average annual 
energy consumption per capita is $2310.68 \mathrm{Kg}$ equivalent oil, and the annual average GDP per capita is around $\$ 7038$. The least polluting country is Morocco, where TG emissions are lowest, recording an average of 1.21 metric tons per capita. Nevertheless, the most polluting country is Bahrain, followed by Saudi Arabia, whose annual average TG emissions are 24.18 and 15.17 metric tons per capita, respectively. The other countries in the sample are less polluting because their average annual TG emissions are lower than those calculated for the entire sample. As an example, the average annual TG emissions are 3.08 metric tons per capita; Iran has reached the level of 5.20 metric tons per capita, while Tunisia has recorded 1.95 metric tons as TG emissions per year.

Table 1: Summary table of data for all countries combined

\begin{tabular}{llll}
\hline Variable & Obs & Avg & Sd. Dev \\
\hline TG emissions (in metric tons per capita) & 460 & 6.20 & 7.24 \\
Energy Use (in Kg oil equivalent per capita) & 460 & 2310.68 & 3067.39 \\
GDP per capita(constant price \$: 2015) & 460 & 7038.53 & 7038.82 \\
\hline
\end{tabular}

Source: calculated by the author from data from the World Bank (WDI, 2017)

Otherwise, the country with very high average annual GDP per capita and average annual energy consumption is Bahrain with \$ 20579.38 and $10594.28 \mathrm{Kg}$ equivalent oil per capita respectively. These are significantly higher than those calculated for all the countries in the sample whose values are $\$ 7038.53$ for GDP per capita and $2310.68 \mathrm{Kg}$ oil equivalent per capita for energy consumption. Turkey is breaking the rule because the average annual consumption of energy is lower (1112.67 Kg oil equivalent per capita), it is lower than that of the sample. However, the average annual GDP per capita is lower with a value of $\$ 8106.51$.

Table 2: Average annual per capita values of TG, Energy and GDP during the period 1987 to 2017

\begin{tabular}{llll}
\hline Country & Avg(TG) & Avg(E) & Avg(GDP) \\
\hline Alegria & 3.08 & 913.64 & 3834.36 \\
Bahrain & 24.18 & 10594.28 & 20579.38 \\
Egypt & 1.74 & 634.91 & 1861.05 \\
Iraq & 3.41 & 1146.41 & 3466.09 \\
Iran & 5.20 & 1836.10 & 4523.18 \\
Jordan & 2.99 & 949.94 & 3075.65 \\
Morroco & 1.21 & 386.37 & 2043.84 \\
Saudi Arabia & 15.17 & 4821.56 & 19894.70 \\
Tunisia & 1.95 & 710.88 & 2900.53 \\
Turkey & 3.09 & 1112.67 & 8106.51 \\
\hline
\end{tabular}

Source: developed by the author using data from WDI (2017), World Bank. 


\section{Estimation Results and Discussion}

The results of the estimates for equation (2), reported in Table 3, were obtained taking into account two types of models: the fixed-effect model and the effect model. random. Indeed, the Hausman test (1978) was used to identify which of these two models is most appropriate and identify the nature of the relationship between TG emissions, energy consumption and economic growth. To do this, the hypothesis $H_{0}$, where the random effect model is the most appropriate, against the alternative hypothesis $H_{1}$ which states that the fixed-effect model is the most appropriate, will be tested. Indeed, column (I) reports the estimation results of the fixedeffect model, while column (II) contains those of the random-effect model. The value of the Housman test is 16.02 , and the probability of rejecting $H_{0}$ is less than $5 \%(0.006)$. Therefore, we reject the null hypothesis, so the model chosen is the fixed effect one. The latter model shows that TG emissions in the MENA region countries are strongly and positively influenced by energy consumption and the level of economic growth, as the coefficients associated with $\operatorname{Ln}(E)$ and $\operatorname{Ln}(G D P)$ are positive and statistically significant(threshold designification $1 \%$ ). Nevertheless, the coefficients of the crossword and the quadratic terms are insignificant, which leads us to test the validity and robustness of this model (fixed-effect model).

Table 3: Estimation results of equation (2) for different specifications

\begin{tabular}{|c|c|c|c|c|}
\hline \multicolumn{5}{|c|}{ Variable to explain: $\operatorname{Ln}(T G)$} \\
\hline Variable & (I) & (II) & (III) & (IV) \\
\hline $\boldsymbol{A}$ & $\begin{array}{c}0.03 \\
(0.018)\end{array}$ & $\begin{array}{c}0.01 \\
(0.032)\end{array}$ & 0.00 & 0.00 \\
\hline $\operatorname{Ln}(E)$ & $\begin{array}{c}0.63 * * * \\
(0.036)\end{array}$ & $\begin{array}{l}0.60 * * * \\
(0.033)\end{array}$ & $\begin{array}{c}0.86 * * * \\
(0.020)\end{array}$ & $\begin{array}{c}0.87 * * * \\
(0.010)\end{array}$ \\
\hline $\operatorname{Ln}(G D P)$ & $\begin{array}{c}0.28 * * * \\
(0.037)\end{array}$ & $\begin{array}{c}0.26^{* * * *} \\
(0.034)\end{array}$ & $\begin{array}{c}0.11 * * * \\
(0.025)\end{array}$ & $\begin{array}{c}0.13^{* * * *} \\
(0.013)\end{array}$ \\
\hline $\begin{array}{l}{[\operatorname{Ln}(G D P)]} \\
*[\operatorname{Ln}(E)]\end{array}$ & $\begin{array}{c}-0.09 \\
(0.102)\end{array}$ & $\begin{array}{c}0.02 \\
(0.096)\end{array}$ & $\begin{array}{c}0.16^{*} \\
(0.095)\end{array}$ & $\begin{array}{l}0.46^{* * * *} \\
(0.052)\end{array}$ \\
\hline $\operatorname{Ln}\left(G D P^{2}\right)$ & $\begin{array}{c}0.10 \\
(0.082)\end{array}$ & $\begin{array}{c}0.03 \\
(0.081)\end{array}$ & $\begin{array}{c}-0.07 \\
(0.100)\end{array}$ & $\begin{array}{c}-0.039 * * * \\
(0.056)\end{array}$ \\
\hline $\operatorname{Ln}\left(E^{2}\right)$ & $\begin{array}{c}0.002 \\
(0.124)\end{array}$ & $\begin{array}{c}-0.10 \\
(0.115)\end{array}$ & $\begin{array}{c}-0.23 * * * \\
(0.096)\end{array}$ & $\begin{array}{c}-0.55 * * * \\
(0.052)\end{array}$ \\
\hline model & Fixed Effect & Random Effect & $\begin{array}{l}\text { FGLS, p(c), } \\
\mathrm{c}(\operatorname{ar} 1)\end{array}$ & FGLS, $\mathrm{p}(\mathrm{c})$ \\
\hline Nb. Obs & 460 & 460 & 460 & 460 \\
\hline & $\begin{array}{l}\text { Hausma } \\
\text { Prob(te }\end{array}$ & $\begin{array}{l}\text { Test: } 16.02 \\
-H)=0.006\end{array}$ & $\begin{array}{l}\text { Wild Kh2: } \\
27712.60 \\
\text { Prob }=0.00\end{array}$ & $\begin{array}{l}\text { Wild Kh2: } \\
280240.43 \\
\text { Prob }=0.00\end{array}$ \\
\hline
\end{tabular}

Source: developed by the author using the software Stata. 
$R k:(* * *),(* *),(*)$ means that the coefficient is respectively significant at 1\%, 5\% and 10\%. The values in (.) Represent the standard deviations.

The various validation tests on the fixed-effect model, namely the autocorrelation of errors, heteroscedasticity and multi-collinearity tests in the panel data, show that this is not robust and presents many shortcomings by making them unable to explain the relationship between the endogenous variable (TG emissions) and the explanatory variables (energy consumption and economic growth). Indeed, the null hypothesis $\left(H_{0}\right)$ of absence of heteroscedasticity errors was via the modified Wald test, presented by Greene (2000). Then the result of this test shows that the associated probability is 0.00 . It is less than 0.05 , which means the rejection of the null hypothesis $\left(H_{0}\right)$ at the $5 \%$ significance level, and therefore the errors are heterologous. In addition, Wooldridge's test shows that the null hypothesis of no selfcorrelation of errors is rejected at the 5\% significance level. As for the test on the presence, or not, of multi-collinearity, the results of the Breusch-Pagan LM test prove the presence of dependence between the individuals of the panel, that is to say we accept the alternative hypothesis $\left(H_{1}\right)$ which advocates the presence of dependence between the individuals of the panel. The detailed results of different tests are reported in the appendix of this article.

In order to overcome these technical problems, equation (2) will be re-estimated using the Feasible Generalized Least Squares (FGLS) regression method. The latter makes it possible to provide robust estimators in the case of the presence of autocorrelation, heteroscedasticity, and multi-collinearity. The results obtained, according to the different specifications, are recorded in columns (III) and (IV) of Table 3. Indeed, column (III) presents the results of the estimation of equation (2) by the FGLS method taking into account in the dummy variables model, heteroscedasticity, autocorrelation and contemporary correlation.

The results show that per capita energy consumption and GDP per capita positively influence TG emissions in the countries included in the study (at the $1 \%$ level of significance). The estimated coefficients are elasticities with values of 0.86 for energy consumption per capita and 0.11 for GDP per capita. This means that when energy consumption increases by one unit, then TG emissions increase by $0.86 \%$, while an additional unit in GDP per capita will boost TG emissions by $0.11 \%$. As a result, environmental degradation within the MENA region is much more dependent on the use of fossil energy than on economic growth. These results corroborate indeed those obtained by previous work. Moreover, the coefficient associated with the crossword appears with a positive and significant sign at the $10 \%$ threshold. 
This means the presence of a feedback relationship between energy consumption and economic growth in selected countries. In other words, energy consumption has a positive influence on GDP per capita, which in turn has a positive impact on energy consumption.

This result is consistent with economic theory and much empirical work supporting the idea that energy use is one of the key drivers of economic growth. As for the quadratic terms $\left(\operatorname{Ln}\left(G D P^{2}\right), \operatorname{Ln}\left(E^{2}\right)\right)$, the associated coefficients appear with negative signs, however that of $\left(\operatorname{Ln}\left(G D P^{2}\right)\right)$ is not significant and that of $\left(\operatorname{Ln}\left(E^{2}\right)\right)$ is very significant (threshold of $\left.1 \%\right)$. Column (IV) reports the estimation results of equation (2) also using the FGLS method taking into account the presence of dummy variables, heteroscedasticity, autocorrelation and contemporary correlation. This column shows that TG emissions in MENA countries are positively impacted by energy consumption and GDP per capita. The elasticity associated with the energy variable remains well above that of economic growth. So if energy consumption and GDP per capita increase by one unit, TG emissions will also increase by $0.87 \%$ and $0.13 \%$ respectively.

These results are consistent with the results of previous work on countries in the MENA region. This work has confirmed the presence of a strong relationship between energy use, the level of economic growth and the degradation and environment of MENA countries. According to Omri (2013), economic growth positively influences TG emissions and vice versa, that is, a feedback relationship. However, the use of energy impels the released amounts of TG, ie the relationship goes in one direction. In addition, the cross-elasticity also remains positive is statistically very significant, confirming the complementarity relationship between energy consumption and economic growth. This result corroborates the conclusions reached by Ghali and El-Sakka (2004), and Apergis and Payne (2009). These authors confirmed the presence of a relationship of feedback and complementarity between economic growth and the level of energy use. This implies that the rate of economic growth depends heavily on the use of energy and vice versa. With regard to the quadratic term of GDP per capita, this time the estimation results show that the estimated coefficient has a negative sign and statically is very significant. This means that the relationship between TG emissions and economic growth is concave. Because the estimated coefficient of $\operatorname{Ln}(G D P)$ is positive, while the coefficient associated with $\operatorname{Ln}\left(G D P^{2}\right)$ is negative. From an economic point of view, such a result means that the curve that traces the evolution of TG emissions according to GDP per capita is characterized by three phases. 
The first phase is the economic development phase in which TG emissions have an upward trend, followed by the stabilization phase, when TG emissions start to stagnate. However, the third phase is one of an advanced level of economic growth where the TG emissions curve is reversed, then trending downward. This curve then takes the form of an inverted U, which leads us to confirm the hypothesis of the KEC. Moreover, the negative sign of the quadratic coefficient $\left(\operatorname{Ln}\left(E^{2}\right)\right)$ can be explained by the relation of complementarity between economic growth and energy consumption, because with an advanced level of economic growth, the use of clean energy and new technologies to produce goods and services is essential, which does not favor TG emissions.

\section{Conclusion}

The purpose of this article was to highlight the issue of the relationship between economic growth and environment in 10 MENA countries during the period from 1987 to 2017. In other words, the relationship between TG, energy consumption and GDP per capita were analyzed to test the hypothesis of the KEC. The methodology used is based on a functional form of translog type in panel data. The results obtained confirm the KEC hypothesis. In addition, GDP per capita and energy consumption positively influence TG emissions, and the presence of a feedback relationship between energy consumption and GDP per capita. Indeed, TG emissions are strongly influenced by energy consumption, as the results show that when energy consumption increases by one unit, TG emissions also increase with a percentage that varies between $0.86 \%$ and $0.87 \%$. However, if GDP per capita increases by one unit, TG emissions will increase by $0.11 \%$ and $0.13 \%$. As a result, the environmental framework of the selected countries improves as their level of economic development has become more advanced.

In the light of these results, some recommendations can be made. Countries in the MENA region are called on to promote renewable energies as a substitute for fossil fuels, boosting the rate of economic growth on the first time, and reducing the TG emissions responsible for the effect greenhouse on the other time. Therefore, it is strongly recommended to provide incentives, such as tax incentives, to encourage investment in renewable energy (clean energy), and investment in technological innovation to produce equipment that consume less energy and emit less greenhouse gases. 


\section{Bibliography:}

1. Al-Mulali,U.,Saboori,B. \& Ozturk,I. ( 2015). Investigating the environmental Kuznets curve hypothesis in Vietnam. Energy Policy 76, 123-131. https://doi.org/10.1016/j.enpol.2014.11.019

2. Apergis, N. \& Payne, J. E. (2009), Energy consumption and economic growth in Central America: Evidence from a panel cointegration and error correction model. Energy Economics 31, 211-216. https://doi.org/10.1016/j.eneco.2008.09.002

3. Arouri, M. E. H., Youssef, A. B., M'henni, H. \& Rault, C. (2012). Energy consumption, economic growth and $\mathrm{CO} 2$ emissions in Middle East and North African countries. Energy Policy, 45, 342-349. https://doi.org/10.1016/j.enpol.2012.02.042

4. Asafu-Adjaye, J. (2000). The relationship between energy consumption, energy prices, and economic growth: time series evidence from Asian developing countries. Energy Econ. 22, 615-625. https://doi.org/10.1016/S0140-9883(00)00050-5

5. Babu, S. S. \& Datta, S. K. (2013). The relevance of environmental Kuznets curve $(\mathrm{EKC})$ in a frame works of broad-based environmental degradation and modified measure of growth- a pooled data analysis. Int. J. Sustain. Dev. World Ecol. 20, 309316. https://doi.org/10.1080/13504509.2013.795505

6. Bélaïd, F. \& Youssef, M. (2017). Environmental degradation, renewable and nonrenewable electricity consumption, and economic growth: Assessing the evidence from Algeria. Energy Policy 102, 277-287. https://doi.org/10.1016/j.enpol.2016.12.012

7. Bouznit M. \& Pablo-Romero, M. (2016). CO2 emission and economic growth in Algeria. Energy Policy 96, 93-104. https://doi.org/10.1016/j.enpol.2016.05.036

8. Chandran, V.G.R. \& Tang,C.F. (2013). The impacts of transport energy consumption, foreign direct investment and income on $\mathrm{CO} 2$ emissions in ASEAN-5 economies. Renew. Sustain. Energy Rev.24, 445-453. https://doi.org/10.1016/j.rser.2013.03.054

9. Christensen L. R., Jorgenson D. W. \& Lawrence J. L. (1973). Transcendental logarithmic production frontiers. The Review of Economics and Statistics 55, No. 1, 28-45. https://doi.org/10.2307/1927992

10. Du, L., Wei, C. \& Cai, S. (2012). Economic development and carbon dioxide emissions in China: provincial panel data analysis. China Econ. Rev. 23, 371-384. https://doi.org/10.1016/j.chieco.2012.02.004 
11. Farhani, S., \& Shahbaz, M. (2014). What role of renewable and non renevable electricity consumption and output is needed to initially mitigate $\mathrm{CO} 2$ emissions in MENA region? Renew. Sustain. Energy Rev.40, 80-90. https://doi.org/10.1016/j.rser.2014.07.170

12. Ghali, Khalifa H. \& El-Sakka, M.I.T. (2004). Energy use and output growth in Canada: a multivariate cointegration analysis. Energy Economics, 26, 225-238. https://doi.org/10.1016/S0140-9883(03)00056-2

13. Greene W. H. (2000). Econometric Analysis 4th Edition. Upper Saddle River, NJ: Prentice-Hall. USA.

14. Holtz-Eakin, D. \& Selden, T. M. (1995). Stoking the fiers? CO2 emissions and economic growth. Journal of public Economics, 57, 85-101. https://doi.org/10.1016/0047-2727(94)01449-X

15. Jalil, A. \& Feridun, M. (2011). The impact of growth, energy and financial development on the environment in China: a cointegration analysis. Energy Econ.33, 284-291. https://doi.org/10.1016/j.eneco.2010.10.003

16. Jayanthakumaran, K. \& Ying-Liu, R. V. (2012). CO2 emissions, energy consumption, trade and income: A comparative analysis of China and India. Energy Policy 42, 450460. https://doi.org/10.1016/j.enpol.2011.12.010

17. Lindmark, M. (2002). Analysis an EKC-pattern in historical perspective: carbon dioxide emissions, technology, fuel prices and growth in Sweden 1870-1997. Ecological Economics 42, 333- 347. https://doi.org/10.1016/S0921-8009(02)00108-8

18. Lucas R. E. (1988). On the mechanics of economic development. Journal of Monetary Economics, Vol. 22, No. 2, 3-42. https://doi.org/10.1016/0304-3932(88)90168-7

19. Narayan, P. K. \& Narayan, S. (2010). Carbon dioxide emissions and economic growth: panel data evidence from developing countries. Energy Policy 38 (1), 661-666. https://doi.org/10.1016/j.enpol.2009.09.005

20. Onafowora, Olugbenga A. \& Owoye, O. (2014). Bounds testing approach to analysis of the environment Kuznets curve hypothesis. Energy Economics 44, 47-62. https://doi.org/10.1016/j.eneco.2014.03.025

21. Osabuohien, E. S., Efobi, U. R. \& Gitau, C. M. W. (2014). Beyond the environmental Kuznets curves in Africa: evidence from panel cointegration. J. Environ. Policy Plan. 16, 517-538. https://doi.org/10.1080/1523908X.2013.867802 
22. Ozcan, B. (2013). The nexus between carbon emissions, energy consumption and economic growth in Middle East countries: a panel data analysis. Energy Policy 62, 1138-1147. https://doi.org/10.1016/j.enpol.2013.07.016

23. Ozturk, I. \& Acaravci, A. (2010). CO2 emissions, energy consumption and economic growth in Turkey. Renewable and Sustainable Energy Reviews 14, 3220-3225. https://doi.org/10.1016/j.rser.2010.07.005

24. Pablo-Romero, M. del P. \& Sánchez-Braza, A. (2015), Productive energy use and economic growth: Energy, physical and human capital relationships. Energy Economics 49, 420-429. https://doi.org/10.1016/j.eneco.2015.03.010

25. Panayotou, T. (1993). Empirical tests and policy analysis of environmental degradation at different stages of economic development. Working Paper WP238, Technology and Employment Programme, International. Labour Office, Geneva.

26. Romer P. M. (1986). Increasing returns and long-run growth. Journal of Political Economy, Vol. 94, No. 5, 1002-1037. https://doi.org/10.1086/261420

27. Saboori, B. \& Sulaiman, J. (2013). Environmental degradation, economic growth and energy consumption: evidence of the environmental Kuznets curve in Malaysia. Energy Policy 60, 892-905. https://doi.org/10.1016/j.enpol.2013.05.099

28. Shahbaz, M., Khraief, N., Uddin, G. S. \& Ozturk, I. (2014). Environmental Kuznets curve in anopen economy: a bounds testing and causality analysis for Tunisia. Renew. Sustain. Energy Rev. 34, 325-336. https://doi.org/10.1016/j.rser.2014.03.022

29. Stern, D. (2000). A multivariate cointegration analysis of the role of energy in the US macroeconomic, Energy Economics, 22 (2), 267-283. https://doi.org/10.1016/S01409883(99)00028-6

30. Wooldridge, Jeffrey M. (2002). Econometric analysis of cross section and pandel data. Cambridge: MIT Press. UK.

31. Yang, H. (2000). A note on the causal relationship between energy and GDP in Taiwan. Energy Econ. 22, 309-317. https://doi.org/10.1016/S0140-9883(99)00044-4 